\title{
STUDI EKSPLORATIF HASIL GAMBAR ANAK USIA 4 DAN 6 TAHUN
}

\author{
Hartosujono \\ Fakultas Psikologi \\ Universitas Sarjanawiyata Tamansiswa \\ J1 Kusumanegara No. 157 Yogyakarta \\ jnsepsi@yahoo.com.
}

\begin{abstract}
This research aimed to compare the picture drawn by children aged 4 and 6 year old. 68 students of kindergarten school and in grade one (first year) of elementary school involved as participants were asked to draw a person then assessed based on Florence Goodenough list which revised by Harrish (1963). To avoid bias, the result of the drawing scored by drawing teacher and psychology lecturer. Score will be given if there are any similarity score filled in both form in the same child. The result indicated that there are differences and similarities between the picture drawn by children aged 4 and 6 years old.
\end{abstract}

Keyword: Age 4 Year, Age 6 Year, Result of Child Picture.

\begin{abstract}
Abstrak
Penelitian ini bertujuan untuk membandingkan bagaimana gambar pada anak-anak berusia 4 dan 6 tahun. Subjek adalah anak yang bersekolah di tingkat Taman Kanak-kanak (TK) dan siswa yang duduk di bangku kelas 1 Sekolah Dasar. Mereka diminta menggambar orang yang kemudian dinilai berdasar daftar Florence Goodenough yang direvisi oleh Harrish (1963). Subjek yang berpartisipasi berjumlah 68 siswa. Hasil gambar tersebut agar menghindari bias, diskor oleh guru gambar dan dosen psikologi. Nilai akan diberikan, bila ada kesamaan nilai yang diisi pada kedua form pada satu anak. Hasil penelitian ini menunjukkan bahwa ada beberapa segi perbedaan dan persamaan antara gambar anak usia 4 dan 6 tahun.
\end{abstract}

Kata kunci: Hasil Gambar Anak, Usia 4 Tahun, Usia 6 Tahun. 


\section{Pendahuluan}

Hurlock (1994) menyatakan bahwa perkembangan anak dipengaruhi dua sisi penting, yaitu kematangan dan belajar. Pertama pada fungsi kematangan, individu memaksimalkan kemampuan yang dimiliki. Kedua, belajar adalah kemampuan dari luar atau lingkungan, yang diserap oleh individu agar menjadi bagian dari dirinya. Kemampuan dapat cepat menjadi bagian dari individu, maka dalam proses belajar tersebut membutuhkan latihan dan usaha.

Umur seorang anak seharusnya menunjukkan tingkat kemampuan koordinasi yang dimilikinya. Kemampuan koordinasi anak dapat diketahui dengan cara meminta anak untuk menggambar. Kemampuan koordinasi tersebut terdapat perbedaan pada anak usia 4 tahun, 6 tahun, dan 8 tahun (Ringenbacah dan Amazeen, 2005). Perbedaan koordinasi motorik ini dapat dilihat secara nyata pada hasil gambar yang anak-anak. Penelitian Hollis dan Low (2005) menunjukkan bahwa kejelasan tugas-tugas yang harus dilakukan anak dapat mengarah pada fleksibilitas penyelesaian tugas menggambar. Bertambahnya usia anak akan menghasilkan gambar yang makin sesuai dengan kenyataan. Anak yang berusia lebih tua, lebih dapat menyajikan hasil gambar yang memiliki kedekatan dengan realitas. Hasil gambar seorang anak akan menunjukkan pengolahan informasi yang diberikan, dan fungsi pengarahan lingkungan, serta kompleksitas tugas yang diberikan kepada anak.

Gambar yang dihasilkan oleh seorang anak adalah hasil koordinasi antara mata, otak dan tangan dalam mewujudkan suatu bentuk. Thomas dan Silk (1990) menyatakan bahwa menggambar bagi anak merupakan salah satu bentuk permainan, segingga dapat diketahui motif dan fungsi perkembangan baik secara keseluruhan maupun per bagian. Adapun tekanannya adalah pada hasil pada gambar anak tersebut. Hasil gambar anak dapat bermacam-macam tergantung objek minat anak dalam menggambar (Kellog, 1969).

Koppitz's (Cox, 1993) telah meneliti 2000 anak dengan kisaran usia 5 dan 12 tahun. Koppitz's juga melakukan penskoran emosi melalui Draw A Person (DAP). Selain gambar dapat mengukur emosi, hasil gambar anak dapat juga digunakan untuk mengukur kemampuan sosial, interaksi dengan orang tua, ada-tidaknya masalah perilaku, deteksi hambatan mental dan perkembangan kognitif(Konold dan Pianta, 2005; Stiles, Joan dkk., 2000).

Terdapat penelitian yang menyebutkan bukti-bukti bahwa gambar anak-anak memiliki tahapan, seperti pernyataan dari Piaget dan Inhelder (Thomas dan Silk, 1990). Hal ini akan diuraikan berdasarkan pembagian umur sebagai berikut: 
1. Usia delapan belas (18) bulan dan dua setengah $(2,5)$ tahun. Sejumlah gambar anak-anak masih bersifat coret-coretan, yang menyatakan coret-coretan tersebut tidak mengandung arti, tetapi ada makna kuat dan dominan pada 'respon motorik'.

2. Usia dua setengah $(2,5)$ tahun hingga lima (5) tahun. Pada usia di atas tiga (3) setengah tahun, tahapan figur manusia ini selalu memiliki figur lingkaran sebagai kepala (atau kombinasi kepala dan tubuh) dan dua garis panjang untuk kaki, yang biasa disebut 'tadpole'.

3. Usia lima (5) tahun hingga enam (6) tahun. Gambar anak pada usia ini, terkadang ada bagian tubuh yang seharusnya tersembunyi namun masih kelihatan. Hasil gambar yang sering disebut dengan transparansi.

4. Pada usia enam (6) tahun hingga masa remaja (sekitar 12 tahunan), terdapat usaha guna menggambar dengan dimensi, dan hubungan antar objek.

Perlu diperhatikan dalam gambar seorang anak adalah bagaimana peletakan bentuk dan persamaan garis. Juga sangat penting dalam kombinasi sederhana dari bentuk dan garis untuk membuat gambar yang lebih kompleks. Perlu juga melihat yang berkaitan dengan posisi baik bagian-bagian tubuh, urutan gambar bagian-bagian tubuh, perencanaan besarnya tubuh.

Berbagai pandangan tersbut mengindikasikan bahwa ada tahapan tertentu dan perbedaan kemampuan koordinasi dari hasil gambar, pada anak untuk usia 4 dan 6 tahun (Ringenbacah \&Amazeen, 2005). Tujuan penelitian ini hendak melakukan observasi, bagaimanakah bentuk-bentuk gambar dan yang membedakan hasil gambar anak normal pada usia 4 dan 6 tahun.

\section{Metode Penelitian}

Variabel yang terlibat dalam penelitian ini adalah hasil gambar orang pada anakanak normal usia 4 tahun (Taman Kanak-kanak) dan usia 6 tahun (klas I Sekolah Dasar). Subjek penelitian adalah anak- anak di Sekolah Kalam Kudus, beralamat di jalan Jambon nomor 4 Yogyakarta.

Tabel 1. Komposisi Kelas, Usia, Jenis Kelamin dan Jumlah Anak

\begin{tabular}{lcccc}
\hline \multicolumn{1}{c}{ Kelas } & Usia (Tahun) & Laki-laki & Perempuan & Jumlah \\
\hline TK A & 4 & 20 & 15 & 35 \\
\hline Kelas 1 & 6 & 16 & 17 & 33 \\
\hline Jumlah & & 36 & 32 & 68 \\
\hline
\end{tabular}


Anak-anak diminta untuk menggambar orang di atas kertas ukuran kwarto (A4) berukuran 21,5 x 29,7 sentimeter. Alat gambar yang disediakan penghapus dan pensil yang berwarna hitam dengan kelunakan setara 2B. Lama waktu yang diberikan tidak dibatasi. Hasil gambar anak kemudian dinilai. Penilaian tersebut berdasarkan ada tidaknya kelengkapan hasil gambar yang disesuaikan dengan daftar dari Harris (1963).

Bagian-bagian tubuh yang tergambar diberikan nilai 1 (satu), sedangkan yang tidak ada diberikan tanda nol. Tanda 1 (satu) dijumlahkan totalnya dan menjadi data mentah (raw score). Pemberian nilai ini akan dilakukan oleh 1 (satu) dosen psikologi dan 1 (satu) guru gambar. Pemberian nilai dilakukan oleh dua orang agar menghindarkan bias. Mereka diminta menilai dengan mengisi formulir yang telah disediakan tanpa harus bertemu untuk berunding. Kedua formulir yang telah diisi akan diperbandingkan. Anak mendapatkan nilai 1 pada hasil gambar bagian tubuh tertentu, bila masing-masing di daftar penilai terdapat skor 1 (satu).

Penelitian ini menggunakan metode deskriptif kualitatif yang merupakan desain penelitian yang bersifat alamiah, dalam arti peneliti tidak berusaha memanipulasi seting penelitian, melainkan melakukan studi terhadap suatu fenomena tersebut (Purwandari, 1998).

\section{Hasil dan Pembahasan}

Rentang penilaian berdasarkan jumlah adalah penilaian berdasarkan penjumlahan. Setiap anak memiliki skor mentah yang merupakan jumlah nilai yang diperoleh dari hasil gambarnya, penghitungannya berdasarkan penjumlahan angka yang dihitung secara individual. Setiap anak mendapat skor sejumlah 1 (satu) pada bagian tubuh yang digambar. Dari keseluruhan tubuh yang digambar oleh anak, skor tersebut dijumlah untuk mendapat totalnya. Berikut ini tabel penilaian individual untuk usia 4 tahun, Penilaian terendah untuk perempuan berjumlah 14, dan untuk laki-laki minimal 10. Untuk penilaian tertinggi yang dapat dicapai adalah 34 dari 71 butir untuk perempuan, dan 40 dari 73 butir untuk laki-laki. Rentang Penilaian Individual untuk Usia 6 tahun. Teknik pengkategorian yang dilakukan serupa dengan tabel 2.

Teknik pengkategorian dengan cara jumlah skor tertinggi dikurangi terendah, dibagi sesuai kebutuhan kategorinya. Langkah selanjutnya dengan menentukan frekuensi dari sejumlah siswa usia 4 tahun sesuai kategorinya.

Pada penilaian individual untuk usia 6 tahun, penilaian terendah mendapatkan skor berkisar 22 antara 24 untuk laki-laki, dan perempuan memiliki skor 28. Penilaian 
tertinggi dari 39 dari 71 butir untuk perempuan, dan 36 dari 73 butir untuk laki-laki. Hasilnya dapat dilihat pada tabel 3.

Tabel 2. Rentang Penilaian Individual untuk Usia 4 Tahun

\begin{tabular}{ccc}
\hline Kategori & Frekuensi & Jenis kelamin \\
\hline $40-45$ & 1 & Laki-laki \\
\hline $32-39$ & 2 & Perempuan \\
\hline $24-31$ & 12 & Laki-laki \& perempuan \\
\hline $17-23$ & 14 & Laki-laki \& perempuan \\
\hline $10-16$ & 6 & Laki-laki \& perempuan \\
\hline
\end{tabular}

Tabel 3. Rentang Penilaian Individual untuk Usia 6 Tahun

\begin{tabular}{ccc}
\hline Kategori & Frekuensi & Jenis kelamin \\
\hline $37-40$ & 4 & Perempuan \\
\hline $33-36$ & 12 & Laki-laki \& perempuan \\
\hline $29-32$ & 6 & Laki-laki \& perempuan \\
\hline $25-28$ & 8 & Laki-laki \& perempuan \\
\hline $21-24$ & 3 & Laki-laki \\
\hline
\end{tabular}

Rentang penilaian berdasarkan jumlah penghitungan kelompok, adalah pengkategorian hasil gambar anak. Sesuai dengan daftar Harris (1963), hasil gambar anak memiliki ciri utama penghitungannya berdasarkan penjumlahan angka yang dihitung secara berkelompok, dimana setiap kategori usia tertentu berkemungkinan menggambar: bagian-bagian tubuh, atau bagian tertentu pada tubuh dimana anak jarang atau belum dapat menggambarnya.

Anak jarang atau belum menggambar dikarenakan beberapa sebab, seperti: teknik menggambar, perkembangan anak, kesulitan anak mengaplikasikan apa yang dilihat dengan hasil yang digambar, dan pemahaman anak yang masih terbatas. Berikut ini disajikan tabel yang berisi rentang penilaian berdasarkan jumlah bagian tubuh yang digambar berdasarkan jenis kelamin perempuan.

Pada tabel 4 diuraikan rentang penilaian dari hasil gambar berdasarkan usia dan jenis kelamin perempuan. Pada usia 4 tahun dengan jumlah subjek perempuan sebanyak 15 anak; gambar yang pasti ada pada setiap gambar terdapat 6 komponen dari bagian tubuh, yaitu: kepala, mata, hidung, model rambut jenis 1 (rambut lurus), tangan, dan tubuh. Pada usia 6 tahun dengan jumlah subjek perempuan sebanyak 17 
anak; gambar yang pasti ada pada setiap gambar terdapat 15 komponen dari bagian tubuh, yaitu: kepala, mata, pipi, mulut, model rambut jenis 1, indikasi baju, tidak terdapat gambar transparan pada gambar, pakaian lengkap, tubuh, penempatan baju pada tubuh, koordinasi motorik hubungan, koordinasi motorik: garis, pokok koordinasi motorik, pola dan garis yang terarah: garis bentuk kepala, pola dan garis yang terarah: muka.

Tabel 4. Rentang penilaian berdasarkan hasil gambar terbanyak berdasar usia dan jenis kelamin perempuan

\begin{tabular}{cccl}
\hline No & $\begin{array}{c}\text { Usia } \\
(\text { Thn })\end{array}$ & $\begin{array}{c}\text { Jumlah } \\
\text { anak }\end{array}$ & \multicolumn{1}{c}{ Gambar } \\
\hline 1. & 4 & 15 & $\begin{array}{l}\text { Kepala, mata, hidung, model rambut jenis } \\
\text { 1, tangan, tubuh }\end{array}$ \\
\hline 2. & 6 & 17 & $\begin{array}{l}\text { Kepala, mata, pipi, mulut, model rambut } \\
\text { 1, indikasi baju, tidak terdapat gambar } \\
\text { transparan pada gambar, pakaian lengkap, } \\
\text { tubuh, penempatan baju pada tubuh, } \\
\text { koordinasi motorik hubungan, koordinasi } \\
\text { motorik: garis, pokok koordinasi motorik, } \\
\text { pola dan garis yang terarah: garis bentuk } \\
\text { kepala, pola dan garis yang terarah: } \\
\text { muka. }\end{array}$ \\
\hline
\end{tabular}

Tabel 5. Rentang penilaian berdasarkan hasil gambar terbanyak berdasar usia dan jenis kelamin laki-laki

\begin{tabular}{cccl}
\hline No & $\begin{array}{c}\text { Usia } \\
\text { (Thn) }\end{array}$ & $\begin{array}{c}\text { Jumlah } \\
\text { anak }\end{array}$ & \multicolumn{1}{c}{ Gambar } \\
\hline 1 & 4 & 20 & Kepala, mata, kaki, dan tubuh \\
\hline 2 & 6 & 16 & $\begin{array}{l}\text { Kepala, mata, mulut, model rambut jenis1, } \\
\text { tangan, kaki, kaki jenis 1, tubuh, koordinasi } \\
\text { motorik: garis, koordinasi motorik: hubungan, } \\
\text { pokok koordinasi motorik, pola dan garis yang } \\
\text { terarah: garis bentuk kepala, pola dan garis } \\
\text { yang terarah: garis bentuk tubuh, pola dan } \\
\text { garis yang terarah: roman muka, dan teknik } \\
\text { goresan. }\end{array}$ \\
\hline
\end{tabular}


Pada tabel 5 diuraikan rentang penilaian dari hasil gambar terbanyak berdasarkan usia dan jenis kelamin laki-laki. Pada usia 4 tahun dengan jumlah subjek laki-laki sebanyak 20 anak; gambar yang pasti ada pada setiap gambar terdapat 4 komponen dari bagian tubuh, yaitu: kepala, mata, kaki, dan tubuh.

Tabel 6 menyajikan perbandingan antara jenis kelamin perempuan dan lakilaki dalam komposisi banyaknya hasil menggambar bagian-bagian tubuh. Ada perbedaan pada daftar penilaian pada perempuan terdapat 71 butir dan pada lakilaki terdapat 73 butir yang dinilai. Pada usia 4 tahun pada perempuan terdapat 6 bagian tubuh yang tergambar. Usia perempuan pada 6 tahun menunjukkan perbedaan banyaknya jumlah bagian tubuh yang digambar, mencapai hingga 15 bagian tubuh.

Tabel 6. Usia, jenis kelamin dan Jumlah bagian tubuh yang digambar

\begin{tabular}{llc}
\hline Usia & Jenis Kelamin & $\begin{array}{c}\text { Jumlah Bagian tubuh } \\
\text { yang digambar }\end{array}$ \\
\hline 4 & Perempuan & 6 \\
\hline & Laki-laki & 4 \\
\hline 6 & Perempuan & 15 \\
\hline & Laki-laki & 15 \\
\hline
\end{tabular}

Hasil gambar laki-laki pada usia 4 tahun terdapat 4 bagian tubuh yang digambar. Usia laki-laki pada 6 tahun menunjukkan peningkatan yang tinggi pada jumlah bagian tubuh yang digambar, mencapai hingga 15 bagian tubuh.

Pada usia 6 tahun baik perempuan dan laki-laki untuk jumlah bagian tubuh yang digambar memiliki jumlah yang sama. Berdasarkan Tabel 6 maka dapat disimpulkan, adanya perbedaan jumlah bagian tubuh yang digambar pada usia 4 tahun dengan usia 6 tahun pada kedua jenis kelamin. Peningkatan jumlah bagian tubuh yang digambar pada perempuan dari usia 4 tahun dengan 6 tahun, terdapat peningkatan hingga 2,5 kalinya. Pada laki-laki perbedaan usia 4 tahun hingga 6 tahun, terdapat perbedaan hingga 3,3 kalinya.

Rentang penilaian penghitungan berdasarkan rata-rata, dari total anak yang menggambar dibagi dengan jumlah contoh anak sesuai dengan jenis kelamin dan usia dalam penelitian ini. Rentang penilaian rata-rata menunjukkan banyak sedikitnya bagian tubuh yang digambar oleh anak-anak. Rentang penilaian rata-rata digunakan sebagai petunjuk, bagian tubuh yang mana saja pasti digambar oleh subjek penelitian. Hal ini penting diketahui sebagai syarat apa saja yang digambar oleh anak sebagai prioritas 
hasil gambar. Rentang penilaian tertinggi adalah 1,00 dan penilaian terendah adalah 0,00 .

Tabel 7. Penilaian berdasarkan rata-rata hasil gambar

Berdasar jenis kelamin perempuan, kelas dan usia

\begin{tabular}{|c|c|c|c|c|}
\hline Kelas & Usia & Rata-rata & Jumlah & Keterangan \\
\hline \multirow[t]{5}{*}{ TK A } & \multirow[t]{5}{*}{$\begin{array}{c}4 \\
\text { Tahun }\end{array}$} & $0,91-1$ & 13 & $\begin{array}{l}\text { Kepala, mata, hidung, mulut, model } \\
\text { rambut } 1 \text {, tangan, tubuh, mulut, jari- } \\
\text { jari, kaki, kaki 1, dan koordinasi } \\
\text { motorik: garis. }\end{array}$ \\
\hline & & $0,81-0,90$ & 4 & $\begin{array}{l}\text { Pipi, dagu dan dahi, pola dan garis } \\
\text { terarah: garis bentuk kepala, pola dan } \\
\text { garis yang terarah: roman muka. }\end{array}$ \\
\hline & & $0,71-0,80$ & 3 & $\begin{array}{l}\text { Garis hidung, koordinasi motorik: } \\
\text { hubungan, dan pokok koordinasi } \\
\text { motorik. }\end{array}$ \\
\hline & & $0,61-0,70$ & 2 & $\begin{array}{l}\text { Garis rahang dan pokok koordinasi } \\
\text { motorik. }\end{array}$ \\
\hline & & $0,50-0,60$ & 1 & $\begin{array}{l}\text { Tidak terdapat transparansi pada } \\
\text { gambar. }\end{array}$ \\
\hline \multirow[t]{5}{*}{$\begin{array}{l}\text { Kelas } \\
1\end{array}$} & \multirow[t]{5}{*}{$\begin{array}{c}6 \\
\text { tahun }\end{array}$} & $0,91-1$ & 13 & $\begin{array}{l}\text { Kepala, mata, pipi, mulut, model } \\
\text { rambut } 1 \text {, tangan, kaki, kaki 1, tubuh, } \\
\text { koordinasi motorik: hubungan, } \\
\text { koordinasi motorik: garis, pokok } \\
\text { koordinasi motorik, pola dan garis } \\
\text { yang terarah: garis bentuk kepala, } \\
\text { serta pola dan garis yang terarah: } \\
\text { roman muka. }\end{array}$ \\
\hline & & $0,81-0,90$ & 5 & $\begin{array}{l}\text { Hidung, dagu dan dahi, garis rahang, } \\
\text { kaki, dan kaki } 1 .\end{array}$ \\
\hline & & $0,71-0,80$ & 5 & $\begin{array}{l}\text { Leher, detail mata: biji mata, lengan } \\
\text { pada sisi atau sedang menampilkan } \\
\text { aktifitas, jari-jari, dan model rok } \\
\text { hingga lipatan atau hiasan. }\end{array}$ \\
\hline & & $0,61-0,70$ & 0 & Tidak ada yang menggambar. \\
\hline & & $0,50-0,60$ & 3 & Garis hidung, lengan, dan pinggul. \\
\hline
\end{tabular}


Tabel 8

Tabel Penilaian berdasarkan rata-rata hasil gambar

Berdasar jenis kelamin laki-laki, kelas dan usia

\begin{tabular}{|c|c|c|c|c|}
\hline Kelas & Usia & Rata-rata & Jumlah & Keterangan \\
\hline \multirow[t]{5}{*}{ TK A } & \multirow[t]{5}{*}{$\begin{array}{c}4 \\
\text { Tahun }\end{array}$} & $0,91-1$ & 7 & $\begin{array}{l}\text { Kepala, mata, mulut, tangan, } \\
\text { kaki, tubuh, dan koordinasi } \\
\text { motorik: hubungan. }\end{array}$ \\
\hline & & $0,81-0,90$ & 2 & $\begin{array}{l}\text { Hidung, dan pola dan garis yang } \\
\text { terarah: garis bentuk kepala. }\end{array}$ \\
\hline & & $0,71-0,80$ & 3 & $\begin{array}{l}\text { Pokok koordinasi motorik, pola } \\
\text { dan garis yang terarah: roman } \\
\text { muka, dan teknik bergaya }\end{array}$ \\
\hline & & $0,61-0,70$ & 3 & $\begin{array}{l}\text { Rambut 1, jari-jari, koordinasi } \\
\text { motorik: garis, dan teknik } \\
\text { goresan. }\end{array}$ \\
\hline & & $0,50-0,60$ & 5 & $\begin{array}{l}\text { Garis rahang, dimensi dagu: } \\
\text { dagu yang bersih dibedakan dagu } \\
\text { di bawah bibir, dagu dan dahi, } \\
\text { garis hidung, telinga, dan } \\
\text { gerakan tangan }\end{array}$ \\
\hline \multirow[t]{5}{*}{$\begin{array}{l}\text { Kelas } \\
1\end{array}$} & \multirow[t]{5}{*}{$\begin{array}{c}6 \\
\text { Tahun }\end{array}$} & $0,91-1$ & 13 & $\begin{array}{l}\text { Kepala, mata, mulut, model } \\
\text { rambut 1, jari-jari, tubuh, } \\
\text { koordinasi motorik: garis, } \\
\text { koordinasi motorik: hubungan, } \\
\text { pokok koordinasi motorik, pola } \\
\text { dan garis yang terarah: garis } \\
\text { bentuk kepala, pola dan garis } \\
\text { yang terarah: garis bentuk tubuh, } \\
\text { pola dan garis yang terarah: } \\
\text { roman muka, teknik goresan dan } \\
\text { teknik bergaya. }\end{array}$ \\
\hline & & $0,81-0,90$ & 3 & $\begin{array}{l}\text { Leher, tangan di samping atau } \\
\text { sedang melakukan aktifitas, dan } \\
\text { gerakan tangan. }\end{array}$ \\
\hline & & $0,71-0,80$ & 1 & Detail mata: alis atau bulu mata \\
\hline & & $0,61-0,70$ & 3 & $\begin{array}{l}\text { Hidung, hidung: dua dimensi, } \\
\text { dan pokok koordinasi motorik. }\end{array}$ \\
\hline & & $0,50-0,60$ & 3 & $\begin{array}{l}\text { Leher: dua dimensi, jumlah jari } \\
\text { yang benar, dan pergelangan } \\
\text { tangan. }\end{array}$ \\
\hline
\end{tabular}


Tabel 7 menunjukkan beberapa bagian tubuh yang digambar oleh sejumlah anak dengan jenis kelamin perempuan. Jumlah rata-rata yang diperoleh yang dicantumkan pada tabel berikut ini adalah yang berkisar antara 0,50 hingga 1,00 .

Tabel penilaian rata-rata dengan penilaian antara 0,50 - 1 pada usia 4 tahun, berjumlah 23 item. Pada perempuan usia 6 tahun berjumlah 26 item. Jumlah item gambar anak pada usia 4 tahun, justru lebih banyak dibandingkan di usia 6 tahun.

Tabel 8 menerangkan uraian dari beberapa bagian tubuh yang digambar oleh sejumlah anak dengan jenis kelamin laki-laki. Jumlah rata-rata yang diperoleh yang dicantumkan pada tabel berikut ini adalah yang berkisar antara 0,50 hingga 1,00 . Rentangan ini merupakan batas pertengahan antara batas tertinggi pada nilai 1 dan batas pertengahan, yaitu pada nilai 0,50 .

Perbandingan pada tabel 8, berdasarkan rata-rata hasil gambar berdasar kedua jenis kelamin, kelas dan usia. Rata-rata penilaian ukuran yang dipakai adalah penilaian penjumlahan yang dilakukan dengan penghitungan secara vertikal, hasil penjumlahan tersebut dibagi dengan jumlah keseluruhan siswa yang menjadi subjek penelitian. Perbandingan ini penting dilakukan berdasarkan jenis kelamin dan usia, fokusnya terpentingnya adalah memahami kemungkinan butir-butir yang yang digambar anak berdasarkan jenis kelamin. Jenis kelamin seorang anak akan terilihat pada perbedaan hasil gambarnya. Penelitian ini dan keberlanjutannya diharapkan dapat secara bertahap dapat memberikan patokan atau panduan dalam berapa butir item yang digambar berdasar jenis kelaminnya.

Kategori usia diharapkan juga dapat memberikan patokan atau panduan seperti halnya jenis kelamin. Usia dapat menjadi panduan mengenai tahapan perkembangan, dalam setiap aspek kognitif, afektif, dan psikomotorik. Tahapan kemampuan psikomotrik akan dimanifestasikan pada perilaku yang terwujud dan dapat dilihat oleh orang lain. Gambar dapat menjadi alat ukur yang sederhana untuk melihat kemampuan koordinasi gerak. Berikut ini adalah tabel perbandingan penilaian berdasarkan rata-rata hasil gambar berdasar usia, kelas dan jenis kelamin perempuan serta laki-laki.

Anak-anak perempuan menunjukkan kisaran penilaian rata-rata antara 0,5 hingga 1. Ada peningkatan maupun penurunan. Hal itu juga terjadi pada laki-laki. Usia 4 tahun, tanpa membedakan jenis kelamin, jumlah hasil gambar rata-rata berkisar antara 20 hingga 29 item. Perbandingan ini menunjukkan bahwa umur 4 dan 6 tahun, hasil gambar untuk laki-laki dan perempuan tidak memiliki perbedaan yang terlalu berarti. Terdapat selisih 3 angka untuk masing-masing jenis kelamin pada dua kategori usia. 
Tabel 9.

Tabel Perbandingan berdasarkan rata-rata hasil gambar Berdasar usia, kelas, dan jenis kelamin perempuan serta laki-laki.

\begin{tabular}{lclc}
\hline Kelas & Usia & Jenis Kelamin & $\begin{array}{c}\text { Jumlah Hasil } \\
\text { gambar }\end{array}$ \\
\hline \multirow{2}{*}{ TK A } & \multirow{2}{*}{4} & Perempuan & 23 \\
\cline { 3 - 4 } & & Laki-laki & 20 \\
\hline \multirow{2}{*}{ Kelas 1 } & \multirow{2}{*}{6} & Perempuan & 26 \\
\cline { 3 - 4 } & & Laki-laki & 23 \\
\hline
\end{tabular}

Dapat disimpulkan bagian-bagian tubuh yang pasti digambar oleh para subjek penelitian, nilai yang diperoleh dari berbagai bagian tubuh dan perlengkapannya berjumlah 0,5 hingga1,0. Hal ini menunjukkan bahwa jumlah item gambar tersebut makin tinggi nilainya, dan berarti hampir semua anak menggambar bagian itu.

Berbagai teknik penghitungan yang disajikan di atas, merupakan teknik penghitungan yang saling melengkapi. Seorang anak berkemungkinan menggambar bagian tubuh manusia dan perlengkapannya untuk usia 4 tahun. Hal ini menunjukkan bahwa anak usia 4 tahun sudah dapat menggambar bagian tubuh manusia dan perlengkapannya, memiliki jumlah terkecil dengan kisaran jumlah 10 untuk laki-laki dan 14 untuk perempuan. Untuk usia 6 tahun penilaian terendah mendapatkan skor berkisar 22 antara 24 untuk laki-laki, dan perempuan memiliki skor 28. Penilaian tertinggi dari 39 dari 71 butir untuk perempuan, dan 36 dari 73 butir untuk laki-laki.

Penghitungan secara kelompok, seluruh hasil gambar anak tanpa memandang jenis kelamin, usia dan kelas; penggambaran tersebut pasti ada. Hasil beberapa gambar seperti kepala, mata, mulut, tubuh, kaki, dan model rambut jenis 1; bagian-bagian tersebut selalu ada pada hasil setiap gambar. Model rambut yang disepakati pada penelitian ini adalah: model rambut jenis 1: model rambut lurus; model rambut jenis 2 : keriting; model rambut jenis 3: berombak; dan model rambut jenis 4: gabungan dari satu atau lebih dari model rambut jenis 1,2, dan 3, termasuk rambut gimbal. Model rambut yang banyak digambar oleh subjek penelitian adalah model yang pertama atau model rambut lurus.

Penghitungan yang menggunakan rentang penilaian dengan rata-rata, menunjukkan penguatan dari Rentang Penilaian Berdasarkan Jumlah Penghitungan Tertinggi Individual dan Rentang Penilaian Berdasarkan Jumlah Penghitungan Kelompok. Rentang penilaian dengan rata-rata tidak merupakan penghitungan yang berdiri sendiri, melainkan subjek penelitian pasti menggambar sejumlah bagian tubuh. 
Hal ini dapat menjadi indikasi bagi anak normal untuk usia 4 dan 6 tahun, bahwa sejumlah organ tubuh yang pasti digambar seperti yang telah diuraikan di atas.

Peningkatan hasil gambar ini menunjukkan pemahaman dari subjek penelitian para anak untuk menggambar tugas-tugas organ tubuh. Seiring bertambahnya usia, hasil gambar anak makin sesuai dengan kenyataan (Hollis dan Low, 2005). Anakanak yang lebih tua menyadari adanya hal-hal yang perlu digambar, untuk mengkomunikasikan kebutuhan-kebutuhan secara internal, bahwa hasil gambar orang harus menunjukkan sejumlah unsur yang diuraikan di atas. Para subjek penelitian menyelaraskan persepsi internalnya melalui hasil gambar, untuk menyatakan kebutuhan-kebutuhan yang sesuai dengan dirinya. Mereka memahami adanya dimensi yang tidak bisa tergambar, misalnya tubuh yang tertutup pakaian. Persepsi yang diserap melalui berbagai indera, mengarah pada kebutuhan dan pengalaman yang mengarah pada hasil gambar yang dianggap relevan dengan harapan dirinya. Adanya keselarasan ini mengarah pada penggunaan jenis asesoris, yang mengarah penunjukan jenis kelamin (penggunaan anting, gelang, dan kalung pada perempuan; namun tidak pada lakilaki).

\section{Simpulan}

Tanpa memandang usia, jenis kelamin, dan kelas; mereka pasti menggambar bagian berikut: kepala, mata, mulut, tubuh, kaki dan model rambut jenis 1: lurus. Adanya peningkatan jumlah bagian tubuh yang digambar baik pada perempuan dan laki-laki, yaitu pada usia 4 dan 6 tahun. Para anak-anak yang diminta menggambar usia 4 tahun, ada perbedaan pada jumlah bagian tubuh yang digambar dengan anak berusia 6 tahun. Penghitungan dengan menggunakan Goodenough-Harris: Drawing Test Manual, untuk perempuan 71 item, dan 73 item dinilai untuk laki-laki. Pada perempuan dengan usia 4 tahun yang terisi adalah 34 item; untuk laki-laki ada 42 item. Usia 6 tahun untuk jenis kelamin perempuan 39 item dan laki-laki 36 item. Para subjek penelitian memahami bahwa gambar yang disebut gambar manusia harus memiliki sejumlah unsur yang disebutkan secara minimal pada butir nomor 1 . Kebutuhan peningkatan hasil gambar ini menunjukkan kebutuhan bahwa seiring bertambahnya usia, mereka menyadari sejumlah gambar yang tidak mungkin digambar, seperti bagian tubuh yang tertutup pakaian, adanya asesoris penanda jenis kelamin (anting-anting, gelang, atau kalung). 


\section{Daftar Pustaka}

Harris, D. B. (1963). Children's Drawings as Measures of Intellectual Maturity: A Revision and Extension of the Goodenough Draw-a-Man Test. New York: Harcourt Brace.

Hurlock, E.B., (1994). Psikologi Perkembangan: Suatu Pendekatan Sepanjang Rentang Kehidupan. Edisi kelima. Cetakan keempat. Jakarta: Erlangga.

Hollis, S. dan Low, J. (2005). Karmiloff-Smith's RRM distinction between adjunctions and redescription: It's about time (and children's drawings). British Journal of Developmental Psyhcology, 23, 622-644.

Kellogg, R. (1969). Analyzing Children's Art. Palo Alto, CA: Mayfield.

Konold, T.R., dan Pianta, R.C. (2005). Empirically-Derived, Person-Oriented Patterns of School Readiness in Typically-Developing Children: Description and Prediction to First-Grade Achievement. Applied Developmental Science, 9(4), 174-187.

Purwandari, E.K. (1998). Pendekatan Kualitatif dalam Penelitian Psikologi. Jakarta: Fakultas Psikologi UI.

Ringenbacah, S.D., dan Amazeen, P.G. (2005). How Do Children Control Rate, Amplitude, and Coordination Stability During Bimanual Circle Drawing? Ecological Psychology, 17 (1), 1-18.

Stiles, Joan,dkk (2000). Drawing Abilities in William Syndrome: A Case Study. Developmental Neuropsychology, 18(2), 213-235.

Thomas, Glyn V., \& Silk, Angele M.J. (1990). An Introduction to the Psychology of Children's Drawings. New York: New York University Press. 